\title{
Emergency Financial System in China after COVID-19 Outbreak
}

\author{
Zifang Ding ${ }^{1 *}$ \\ ${ }^{1}$ School of Finance, Nanjing Audit Universit, Nanjing, China
}

\begin{abstract}
China has always had frequent disasters, and unexpected emergency public events often bring great impact to the national economy, so it is very important for the emergency financial management mechanism to effectively respond to. Combining with the emergency financial control measures for the new crown pneumonia epidemic, this paper analyses the imperfections of the current emergency financial control system in China from four aspects: contingency, delineation of fiscal responsibilities among central and local financial departments in the field of emergency management, institutionalization of emergency financial system, supervision and management, and puts forward corresponding suggestions and countermeasures.
\end{abstract}

\section{Introduction}

At the end of 2019, a "black swan" event, the COVID-19 outbreak, had a great impact on the economic and social development and social order in China, which was a major challenge for China's economic development. The management of any public emergency cannot do without strong national financial support, so it is necessary to incorporate the financial governance mechanism into the theoretical research of emergency management. The emergency financial operation in China after the outbreak of COVID-19 is an important case in the study of emergency financial management system. Based on the present situation and looking forward to the future, the achievements and progress, shortcomings and shortcomings under the emergency financial management system in the course of epidemic control are studied, and reform plans are put forward, with a view to further improving the emergency financial management system and having extraordinary significance for continuously enhancing disaster response capacity with Chinese characteristics[1-3].

\section{Policy practice of emergency financial management in china during the period of epidemic prevention and control}

In the process of governance, the country will inevitably encounter all kinds of emergency public events, which will cause crisis to the country's economic stability and people's life. It is very important for the financial department to judge the current situation and grasp the direction of future regulation, which is reflected in the timely introduction of effective fiscal policies to reduce people's family economic losses, support the economy and prevent the downward trend from becoming serious. In the process of controlling the epidemic situation, better results have been observed in the emergency financial management, which is manifested in:

The policy of providing free assistance to confirmed and suspected patients with COVID-19. Because the cost of diagnosis and treatment of COVID-19 is very high, in order to relieve the financial burden of the families and prevent and cure the virus effectively, the medical expenses are borne by the state finance, $60 \%$ of which are subsidized by the state central finance department, and only a small part of the expenses need to be borne by families and individuals.

A series of preferential policies for taxes and fees have been launched, with a total of 23 items in 5 batches. Each batch of preferential policies focuses on different objects, targeting to benefit the people affected by the COVID-19 in various fields. The five batches of policies focus on epidemic prevention and control work, social security fees for enterprises, small and micro enterprises and individual businesses, foreign trade stabilization, rural finance and loans for small and micro enterprises. This set of preferential tax and fee policies has expanded the social safety net and covered a wide range of areas, reduced the tax burden of enterprises in industries heavily affected by the epidemic, increased welfare for groups with declining income and profits, protected the interests of affected individuals and enterprise groups, and effectively promoted economic recovery.

The policies of enhancing the stability of enterprises, stimulating vitality, making up for the fiscal deficit, and vigorously increasing the strength of national bond issuance, including issuing 1 trillion RMB of special national debt to fight the epidemic to raise financial funds, promote economic development, and adjust the balance between supply and demand.

The introduction of the "new infrastructure" policy promotes economic development, speeds up the opening and operation of China-Europe freight trains, and promotes rapid economic recovery.

* Corresponding author: 1994541@qq.com 


\section{Some problems in the emergency financial system from the perspective of epidemic control}

Although China has experienced SARS, Wenchuan earthquake and other emergencies, the emergency financial system is still gradually improving in the process of practice. The deficiencies revealed in the emergency financial management after COVID-19 outbreak are as follows:

\subsection{Insufficient financial funds for emergency}

The use of emergency financial funds is an important part of the governance process, and whether the emergency financial funds are sufficient has become one of the important indicators to measure a country's emergency governance capacity. According to the general public budget policy of China, the financial departments at all levels should draw $1 \% \sim 3 \%$ of the general public budget expenditure allocated by the finance at the same level as the reserve expenses, so as to cope with the expenditure of unexpected public events and unpredictable related natural disasters in this year[4,5]. At present, China is in the process of economic transformation and social transformation. Most of the costs of public emergencies and natural disasters are borne by the state. In China's financial management mechanism, the most important fund to deal with emergencies is the budget cost. When implementing the emergency management mechanism, governments at all levels should first mobilize and draw reserve funds, and make budget adjustments when necessary. However, in the process of practice, in recent years, China's reserve funds for preparing for emergencies have appeared the phenomenon of not advancing but retreating, which is reflected in the proportion of reserve funds drawn, showing a downward trend, as shown in Table 1. This situation leads to the difficulty of reserve fund support after the arrival of the epidemic. In fact, according to the statutory reserve fund withdrawal ratio of $1 \%$ to $3 \%$, the withdrawal scale of China's finance at all levels is on the low side. Although the central government still maintains the absolute withdrawal scale of 50 billion RMB per year, the proportion of reserve fund continues to shrink because the scale of financial expenditure is expanding year by year and the growth rate is higher. In addition, scholars are sensitive to the fact that since 2016, the reserve funds of local finance are no longer listed in the local financial budget report. Whether the reserve funds are fully withdrawn by local finance and whether the reserve funds are transferred to other places where they are more needed can't be directly investigated. There is a lack of risk awareness in reserve funds management in China.

TABLE 1. Withdrawal of central and local contingencies in the past 5 years

\begin{tabular}{|c|c|c|c|c|c|c|}
\hline \multirow[b]{2}{*}{ Years } & \multicolumn{3}{|c|}{ Central government } & \multicolumn{3}{|c|}{ Local governments } \\
\hline & $\begin{array}{c}\text { Contingencies } \\
(\text { RMB } 100 \text { million) }\end{array}$ & $\begin{array}{l}\text { Expenditure at this level } \\
\quad(\text { RMB } 100 \text { million) }\end{array}$ & $\begin{array}{l}\text { The proportion of } \\
\text { contingencies to } \\
\text { expenditure at the } \\
\text { corresponding level } \\
\text { (\%) }\end{array}$ & $\begin{array}{c}\text { Contingencies } \\
(\text { RMB } 100 \text { million) }\end{array}$ & $\begin{array}{l}\text { Expenditure at this level } \\
\quad(\text { RMB } 100 \text { million) }\end{array}$ & $\begin{array}{l}\text { The proportion of } \\
\text { contingencies to } \\
\text { expenditure at the } \\
\text { corresponding level } \\
\text { (\%) }\end{array}$ \\
\hline 2015 & 500 & 25012 & 2 & 950 & 145988 & 0.7 \\
\hline 2016 & 500 & 27355 & 1.8 & Unknown & 152860 & Unknown \\
\hline 2017 & 500 & 29595 & 1.6 & Unknown & 164768 & Unknown \\
\hline 2018 & 500 & 32507 & 1.5 & Unknown & 178196 & Unknown \\
\hline 2019 & 500 & 34915 & 1.4 & Unknown & 193758 & Unknown \\
\hline
\end{tabular}

Then, how can the large amount of emergency financial funds required for epidemic prevention and control be replenished in a timely manner? According to the study on relevant reports published by the Ministry of Finance and the epidemic prevention and control emergency headquarters, China mainly adopts the strategy of transferring the existing funds among the central departments to "relieve the emergency". However, this method has obvious disadvantages: due to the insufficient preparation of funds in advance, the practice of slightly mandatory pooling donation of funds has impacted the normal operation of other departments, and may even give rise to more volatile changes in economic development, making the emergency financial management counterproductive and contrary to the requirements of the socialist modern governance system.

\subsection{Imperfect risk sharing mechanism in emergency financial management system and excessive pressure on central finance}

When a public crisis event like a sudden large-scale epidemic occurs, economic subjects are cognitively blurred about the magnitude of risk that they should take. The risks in the emergency financial system will be finally converged to the central finance horizontally and vertically: horizontally, due to the public nature of emergencies, financial institutions, enterprises, individuals and other economic entities will transfer risks to government departments; vertically, risk transfer between financial departments tends to be concentrated from bottom to top, so the central government as the absolute main force needs the central finance to bear tremendous pressure. Although the system of "giving priority to the central finance and supplementing the 
local finance" can relieve the pressure of local finance to a large extent, the goal of local finance is to restore the economy and ensure the people's livelihood to the maximum extent. Thus, it is more and better to have on demand for central financial funding. Whereas there is no clear delineation of fiscal responsibilities among central and local financial departments, and the local financial department knows that the central government has to replenish the funds, making it more difficult to require local governments to do savings when funding is used, and the local government does not have much incentive to conduct rigorous funding management.

The relationship between central finance and local finance has always been a hot topic among scholars. A country's finance is the economic foundation and important guarantee of national governance. A reasonable and clear relationship between central finance and local finance is very important. At present, in the emergency financial management system, the relationship between the central and local governments is still not very clear. The whole society lacks a reasonable risk dispersion mechanism in the face of the epidemic situation. The government bears more concentrated public risks, and the role of society and market is weakened or even hidden. Whether this is really conducive to disaster response and mitigation remains to be discussed.

\subsection{Unclear institutionalization of emergency financial management}

Some scholars have found that various measures introduced during the epidemic in China have been used in various degrees in the past emergency events, such as the post-SARS treatment in 2003, and a more routine and effective emergency financial management system has been formed in China. However, it is a little regrettable that these measures are all once-off, temporary in use and failed to really be institutionalized.

\subsection{Unclear institutionalization of emergency financial management}

Because emergency financial funds are used in special periods and specific areas and have their own particularities, it is often difficult to supervise and evaluate them. Besides, they are designated to deal with the special cases and emergencies, excluded from the strict budget management as ordinary financial funds, often allocated in advance or cleared after the event, which brings opportunities for some corruptors to misappropriate, as reported during the outbreak of COVID-19. At present, the problems in supervision and management of emergency financial expenditure in China lie in the over-emphasis on overall allocation of financial funds, weak supervision and assessment links, large waste of funds and inefficient use of funds.

\section{Suggestions and countermeasures for further improving the emergency financial management system}

\subsection{Adjusting the contingency system and widen the channels of fiscal revenue}

Many scholars have put forward a lot of plans for the reform of the contingency system, with a common point that they hope that the financial departments at all levels will increase the proportion of the contingencies, and the fund management method will be adopted. Figure 1 shows the comparison between the theoretical and actual provision ratio of contingencies in China in recent years. In recent years, the amount of contingencies has failed to cover the actual expenditure, and the gap between the theoretical and the actual amount shows a decreasing trend in general. Overall, the contingency withdrawal ratio should be increased by about $3 \%$.

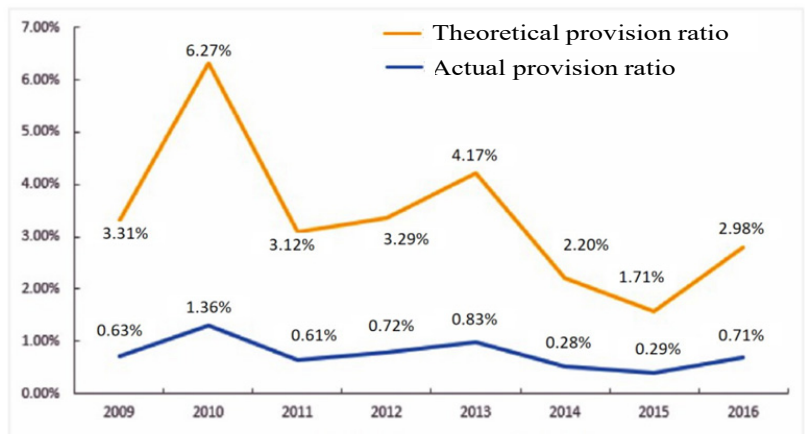

Fig. 1. Comparison between the theoretical and actual provision ratio of contingencies

On the basis of meeting the basic guarantee, we should pay attention to the flexibility of emergency financial fund-raising and expand the channels of fundraising. In 2020, the "tax reduction and fee reduction" policy will continue. Behind the active and promising fiscal policy is a large-scale fiscal deficit. In 2020, the deficit rate is planned to be more than $3.6 \%$, and the scale of fiscal deficit will increase by 1 trillion RMB year on year. How to make up for such a huge fiscal deficit has become a hot topic. Although the report announced that 1 trillion RMB will be issued in the future to fight the epidemic, especially for treasury bonds, it did not specify the form to be issued. How to make up for the fiscal deficit is still a controversial topic, and the issue of "monetization of fiscal deficit" is still hot. In my opinion, the monetization of fiscal deficit can meet the needs of a large number of fiscal expenditure in a short time, but its disadvantages are far greater than the benefits. Firstly, "monetization" of fiscal deficit will break the long-standing balance between fiscal policy and monetary policy, and the function of central bank will not be activated and come into effect; secondly, it will destroy the budget constraint mechanism, and the issuance of treasury bonds with almost no cost can tolerate the further expansion of fiscal deficit, and the budget mechanism will become empty talk; finally, "monetization of fiscal deficit" will take a certain course 
The pricing mechanism of financial market will be distorted and the function of "price discovery" will be weakened. "Monetization of fiscal deficit" has great risks and can not be a good channel to expand emergency financial funds.

\subsection{Bundling the central and local governments and reasonably allocating the responsibilities in respect of expenditure on financial emergency funds}

In the face of unclear sharing of rights and responsibilities of public risks among government departments, it is easy to give birth to moral risks, and the upper and lower departments rely on each other. This system is not conducive to quickly and effectively resolve the public crisis, nor is it conducive to identify in advance to avoid public risks and effectively protect people's livelihood. In this case, it is very necessary to establish and improve the risk sharing mechanism. 2020 is a troubled year for everyone, but it is also the end of many tasks. According to the relevant work plan, the division of financial powers between the central and local governments will also be completed before this node. The division of financial powers between the central and local governments in emergency management should be actively considered in the reform task, and take this opportunity to clarify.

More specifically, because immediate decisionmaking is necessary during the management of sudden public events, the event rights should be ascribed to the local departments. In terms of funds, in dealing with emergencies, financial allocation should be reasonably crossed between the central and local governments and not be fully undertaken by the central government. With regard to the division of responsibility for risk bearing, the central government should gradually institutionalize the division based on the corresponding level of emergency response to emergencies, the level of economic development of the regions affected by disasters and the level of local government resources. If the three-level and four-level emergency response is initiated, the responsibility for emergency management and expenditure of emergency finance shall be jointly borne by the central and local governments; if one-level and two-level emergency response is initiated, the central government shall bear the main responsibility, but a certain proportion (such as about $10 \%$ ) shall be reserved for the local governments, so as to establish the emergency financial mechanism coordinated by the central and local governments.

\subsection{Making up for the shortcomings in the legalization of emergency finance}

Relevant laws and regulations on emergency financial management in China are not complete yet. Besides, there are no clear provisions in the Constitution on how to prepare the financial emergency budget and the proportion of the distribution of the emergency budget expenditure of the finance at all levels. In view of this, it is necessary to introduce scientific performance evaluation indicators into the national financial emergency management system to evaluate the emergency funds, including the management system based on the vague level, the dynamic tracking of the use of emergency funds, the introduction of third party departments to strengthen the constraint of the management system, etc. The construction of a modern emergency management system needs to keep up with the development of the times and be innovative and efficient.

\section{Conclusions}

The changes of the times push forward the changes of theories. Although the emergency management system in China has become more mature, there is still a certain gap between it and the institutionalized emergency financial management system of "touch and go". In terms of contingency, it is necessary to increase the proportion of withdrawal of reserve funds; in terms of fund raising, it is necessary to broaden the funding channels; in terms of the power and responsibility relationship of emergency financial expenditure between the central and local governments, comprehensive and multi-considerations should be taken to achieve a rational distribution of the proportion of risk-bearing allocation between the central and local governments and to reduce moral risks; in terms of comprehensive system management, it is necessary to further improve the legalized management and vigorously improve the quality and efficiency. At present, there is not much research on emergency financial management system in China, and in-depth research on this field is expected so that emergency finance can protect people's livelihood to the greatest extent in the face of sudden crises.

\section{References}

1. F. Qiaobin. Current situation and improvement measures of emergency financial funds management in China. Public Finance Research, pp.12-17, June 2009.

2. F. Qiaobin. China's emergency financial management system refracted by the COVID-19. Fiscal Science, pp.14-20, April 2020.

3. H. Wenzheng, L. Hong. Construction of public finance emergency security mechanism at this stage. Social Sciences in Guizhou, pp.139-143, November 2015.

4. S. Ming, W. Min. China's fiscal expenditure policy for emergency management. China Emergency Management, pp.10-17, February 2015.

5. W. Han, W. Yijun, W. Lianqing, Z. Hong. Fiscal and macro-policy responses to public emergencies. Financial Market Research, pp.24-36, February 2020. 